\title{
ANALISIS FAKTOR PENENTU KEPUASAN KERJA KARYAWAN DAN DAMPAKNYA TERHADAP PELAYANAN PUBLIK PADA RUMAH SAKIT DI KABUPATEN JEMBRANA
}

\author{
Ni Putu Lilyana ${ }^{1}$ \\ Nyoman Djinar Setiawina ${ }^{2}$ \\ ${ }^{1,2}$ Fakultas Ekonomi dan Bisnis Universitas Udayana (Unud), Bali, Indonesia \\ email: dheana180914@gmail.com
}

\begin{abstract}
ABSTRAK
Penelitian ini bertujuan untuk menganalisis budaya organisasi, kepemimpinan, motivasi dan kepuasan kerja karyawan berpengaruh terhadap pelayanan publik rumah sakit, serta menganalisis kepuasan kerja karyawan dapat memediasi antara budaya organisasi, kepemimpinan, dan motivasi terhadap pelayanan publik rumah sakit melalui kepuasan kerja karyawan rumah sakit di Kabupaten Jembrana, dianalisis dengan partial least square (PLS). Lokasi penelitian dilakukan di Kabupaten Jembrana. Jenis data yang digunakan dalam penelitian ini kuantitatif dan kualitatif. Sumber data yang digunakan dalam penelitian ini adalah data primer dari hasil kuisioner kepada responden. Hasil analisis menunjukkan bahwa Budaya organisasi dan motivasi secara langsung berpengaruh positif dan signifikan terhadap kepuasan kerja karyawan, sedangkan kepemimpinan tidak berpengaruh signifikan terhadap kepuasan kerja karyawan rumah sakit. Kepemimpinan, motivasi, dan kepuasan kerja karyawan secara langsung berpengaruh positif dan signifikan terhadap pelayanan publik, namun budaya organisasi tidak berpengaruh signifikan terhadap pelayanan publik rumah sakit. Kepuasan kerja karyawan memediasi secara signifikan pengaruh budaya organisasi dan motivasi terhadap pelayanan publik, namun memediasi secara tidak signifikan pengaruh kepemimpinan terhadap pelayanan publik rumah sakit di Kabupaten Jembrana. Disarankan agar manajemen rumah sakit di Kabupaten Jembrana perlu memberikan training kepemimpinan.
\end{abstract}

Kata Kunci : Kepemimpinan, budaya organisasi, motivasi, pelayanan publik, kepuasan kerja karyawan

\section{ABSTRACT}

This study aims to analyze organizational culture, leadership, motivation and employee job satisfaction influence on hospital public service, and analyze employee job satisfaction can mediate between organizational culture, leadership, and motivation to public service of hospital through job satisfaction of hospital employee in Regency Jembrana, analyzed by partial least square (PLS). The location of the research was conducted in Jembrana District. The type of data used in this study is quantitative and qualitative. Sources of data used in this study is the primary data from the results of questionnaires to respondents. The result of analysis shows that organizational culture and motivation directly have a positive and significant effect on employee job satisfaction, while leadership has no significant effect to the work satisfaction of hospital employees. Leadership, motivation, and job satisfaction of employees directly have a positive and significant impact on public services, but organizational culture has no significant effect on hospital public services. Employee job satisfaction mediates significantly the influence of organizational culture and motivation on public services, but mediates insignificantly the influence of leadership on public service hospitals in Jembrana District. It is recommended that hospital management in Jembrana District need to provide leadership training.

Keywords: Leadership, organizational culture, motivation, public service, employee job satisfaction 
Ni Putu Lilyana, Nyoman Djinar Setiawina, Analisis Faktor Penentu Kepuasan.........

\section{PENDAHULUAN}

Penyelenggaraan tata pemerintahan yang baik (good governance), pelayanan publik merupakan instrumen penting dalam mengukur penyelenggaraan pemerintahan. Konteks inilah organisasi pelayanan publik mempunyai ciri akuntabilitas publik (publik accountability) di mana anggota masyarakat mempunyai hak untuk mengevaluasi kualitas pelayanan yang mereka terima (Hardiyansyah, 2011:42). Dengan demikian, setiap organisasi pelayanan publik harus mampu menempatkan masyarakat sebagai fokus pelayanan (putting customers first). Tatanan realita, melakukan reformasi sistem pelayanan publik sesuai gagasan demokrasi sebagaimana di atas bukanlah hal yang mudah, karena dalam pelaksanaannya bersifat dilematis. Di satu sisi, pemerintah yang professional dan rasional melalui penerapan prinsip-prinsip objektivitas, efisiensi, pertimbangan biaya dan manfaat serta legalitas formal dapat saja dilakukan; sementara di sisi lain, tuntutan terhadap responsivitas yang tinggi seperti kepekaan sosial terhadap kelompok-kelompok masyarakat yang termasuk kategori kurang beruntung (difabel) harus dikedepankan oleh aparat birokrasi. Sebagai konsekuensinya, prinsip-prinsip legalitas dan efisiensi terkadang harus dikorbankan karena yang dipentingkan adalah bahwa birokrasi harus mampu menjadi pelayan yang baik (Kumorotomo, 2008:191).

Dalam pelaksanaan pelayanan di rumah sakit, produktivitas individu maupun kelompok sangat mempengaruhi kualitas pelayanan yang diberikan. Kepemimpinan, budaya organisasi, motivasi serta pelayanan publik merupakan beberapa variabel pendukung yang dapat terpenuhinya persoalan akan kepuasan kerja.

Berdasarkan latar belakang, maka tujuan penelitian ini adalah untuk menganalisis pengaruh budaya organisasi, kepemimpinan dan motivasi terhadap kepuasan kerja karyawan rumah sakit, menganalisis pengaruh budaya organisasi, kepemimpinan, motivasi, dan kepuasan kerja karyawan terhadap pelayanan publik rumah sakit, menganalisis mediasi kepuasan kerja karyawan antara budaya organisasi, kepemimpinan, dan motivasi terhadap pelayanan publik rumah sakit melalui kepuasan kerja karyawan rumah sakit di Kabupaten Jembrana. 


\section{METODE PENELITIAN}

\section{Lokasi Penelitian}

Penelitian dilakukan pada rumah sakit di Kabupaten Jembrana, dengan pertimbangan bahwa RSUD Negara merupakan rumah sakit terbesar di Kabupaten Jembrana. Rumah Sakit Umum (RSU) Negara Kabupaten Jembrana merupakan salah satu SKPD di Kabupaten Jembrana dengan menyelenggarakan 13 unit pelayanan. Rumah Sakit Umum Bunda merupakan rumah sakit swasta, sebagai penunjang pelayanan kesehatan di Kabupaten Jembrana, yang bertujuan untuk meningkatkan kualitas kesehatan masyarakat umum.

\section{Definisi Operasional Variabel}

1) Budaya organisasi $\left(X_{1}\right)$ merupakan suatu kesepakatan bersama para anggota dalam suatu organisasi sehingga mempermudah lahirnya kesepakatan yang lebih luas untuk kepentingan perorangan. Budaya organisasi juga diartikan sebagai perekat sosial yang mengingat anggota dari organisasi. Alat pengukuran yang digunakan adalah dengan skala likert. Budaya organisasi $\left(\mathrm{X}_{1}\right)$, dengan indikator integritas, rasionalitas, solidaritas.

2) Kepemimpinan $\left(\mathrm{X}_{2}\right)$ adalah kemampuan seseorang mempengaruhi dan memotivasi orang lain untuk melakukan sesuatu sesuai tujuan bersama. Alat pengukuran yang digunakan adalah dengan skala likert. Kepemimpinan $\left(\mathrm{X}_{2}\right)$ dengan indikator loyalitas, kepercayaan, komitmen.

3) Motivasi kerja $\left(\mathrm{X}_{3}\right)$ merupakan suatu kondisi yang berpengaruh membangkitkan dorongan dari dalam diri karyawan yang berhubungan dengan lingkungan kerja. Diukur dengan skala likerts.

4) Kepuasan kerja karyawan $\left(Y_{1}\right)$ merupakan sikap positif atau negatif terhadap pekerjaannya yang terkait dengan kondisi kerja dan lingkungan kerja karyawan. Diukur dengan skala likerts.

5) Pelayanan publik atau pelayanan umum $\left(\mathrm{Y}_{2}\right)$ yang diselenggarakan oleh organisasi privat dalam hal ini pelayanan publik untuk kepuasan pasien/masyarakat pengguna jasa rumah sakit. Diukur dengan skala likerts. 
Ni Putu Lilyana, Nyoman Djinar Setiawina, Analisis Faktor Penentu Kepuasan.........

\section{Teknik Analisis Data}

\section{A. Analisis Statistik Inferensial}

Analisis Statistik Inferensial yaitu suatu analisis yang dilakukan untuk menguji hipotesis penelitian yang telah dibuat dimana pada penelitian ini digunakan metode analisis jalur (path analysis) yang sebelumnya dilakukan model pengukuran ditujukan untuk mengkonfirmasi sebuah dimensi atau faktor berdasarkan indikatorindikatornya melalui teknik Confirmatory Factor Analysis (CFA).

Skema diagram jalur penelitian sebagaimana Gambar 1.

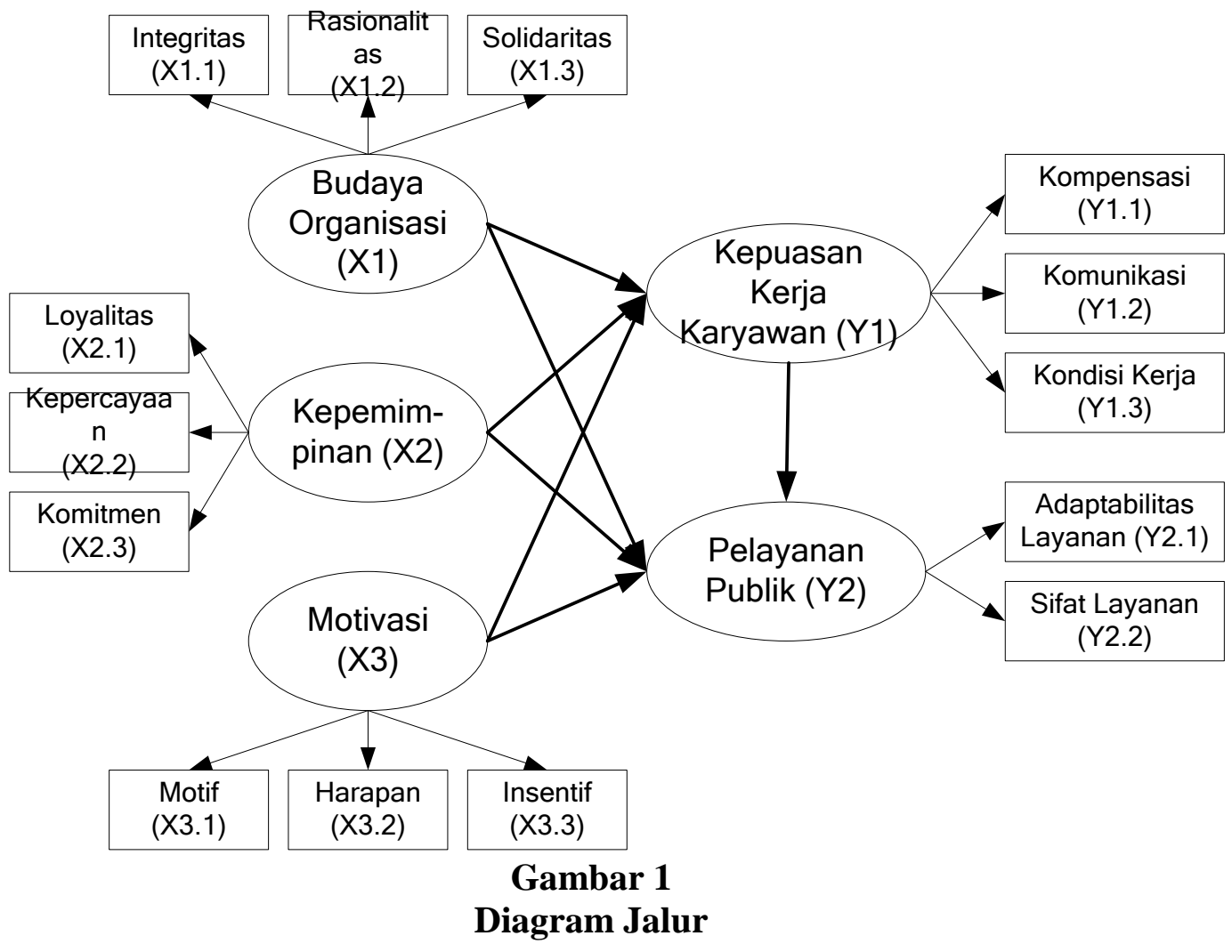

a) Teknik Confirmatory Factor Analysis (CFA) ditujukan untuk mengestimasi measurement model, menguji unidimensionalitas dari konstruk-konstruk eksogen dan endogen. Metode statistik yang digunakan untuk menguji validitas konstruk dari analisis faktor adalah dengan melihat korelasi KMO (KaiserMeyer-Olkin) atau Bartlett's test. Besarnya KMO minimal 0,5 dan jika nilai KMO di bawah 0,5 maka analisis faktor tidak bisa digunakan. Disamping itu, 
faktor yang dipertimbangkan bermakna bilamana eigen value lebih besar dari satu (1) dan varian kumulatifnya minimal 60 persen untuk penelitian-penelitian ilmu sosial (Hair, 1995) seperti Tabel 4.3.

b) Analisis jalur (path analysis) yang secara definitif menurut Sarwono (2007) adalah merupakan sebuah metode yang digunakan untuk melihat akibat (effects) langsung dan tidak langsung dari suatu variabel yang dihipotesiskan sebagai penyebab (causes) terhadap variabel yang diperlakukan sebagai akibat.

c) Merancang model berdasarkan konsep dan teori, (model tersebut juga dinyatakan dalam bentuk persamaan): Model hubungan langsung dapat dituliskan pada persamaan berikut.

$\mathrm{Y}_{1}=\mathrm{a}_{1}+\mathrm{b}_{1} \mathrm{X}_{1}+\mathrm{b}_{2} \mathrm{X}_{2}+\mathrm{b}_{3} \mathrm{X}_{3}+\mathrm{e}_{1}$

$Y_{2}=a_{2}+b_{4} X_{1}+b_{5} X_{2}+b_{6} X_{3}+b_{7} Y_{1}+e_{2}$

Keterangan:

$\mathrm{Y}_{1}=$ Kepuasan kerja karyawan

$\mathrm{Y}_{2}=$ Pelayanan publik (masyarakat pengguna)

$\mathrm{X}_{1}=$ Budaya organisasi

$\mathrm{X}_{2}=$ Kepemimpinan

$\mathrm{X}_{3}=$ Motivasi

$\beta_{1-2-3-4-5}=$ Koefisien regresi.

$\alpha \quad=$ Intersep

$\mathrm{e} \quad=$ Error

B. Analisis Faktor-faktor Yang Mempengaruhi Pelayanan Publik Rumah

\section{Sakit}

Penelitian ini dilakukan untuk menganalisis beberapa faktor-faktor yang mempengaruhi pelayanan publik Rumah Sakit di Kabupaten Jembrana. Koefisien jalur pada penelitian ini diperoleh dari hasil perhitungan regresi dengan metode regresi sederhana (Ordinary Least Square $=O L S$ ) yaitu sebagai berikut :

Model 1 : Pengaruh budaya organisasi (X1), kepemimpinan (X2), dan motivasi (X3) terhadap kepuasan kerja karyawan (Y1).

Model 2 : Pengaruh budaya organisasi (X1), kepemimpinan (X2), motivasi (X3), dan kepuasan kerja karyawan (Y1) terhadap pelayanan publik (Y2). 
Ni Putu Lilyana, Nyoman Djinar Setiawina, Analisis Faktor Penentu Kepuasan.........

\section{Pengaruh Langsung}

Berdasarkan Tabel 1 dan Tabel 2 dapat dibuat ringkasan koefisien jalur seperti yang disajikan pada Tabel 3 di bawah ini :

Tabel 3

Ringkasan Koefisien Jalur

\begin{tabular}{lccccc}
\hline \multicolumn{1}{c}{ Regresi } & $\begin{array}{c}\text { Koef. Reg. } \\
\text { Standar }\end{array}$ & $\begin{array}{c}\text { Standard } \\
\text { Error }\end{array}$ & t hitung & P. Value & Keterangan \\
\hline $\mathrm{X} 1 \rightarrow \mathrm{Y} 1$ & 0.538 & 0.121 & 4.445 & 0.000 & Signifikan \\
$\mathrm{X} 2 \rightarrow \mathrm{Y} 1$ & 0.008 & 0.103 & 0.082 & 0.935 & Non Signifikan \\
$\mathrm{X} 3 \rightarrow \mathrm{Y} 1$ & 0.220 & 0.091 & 2.426 & 0.017 & Signifikan \\
$\mathrm{X} 1 \rightarrow \mathrm{Y} 2$ & 0.085 & 0.104 & 0.815 & 0.417 & Non Signifikan \\
$\mathrm{X} 2 \rightarrow \mathrm{Y} 2$ & 0.183 & 0.082 & 2.236 & 0.027 & Signifikan \\
$\mathrm{X} 3 \rightarrow \mathrm{Y} 2$ & 0.194 & 0.074 & 2.630 & 0.010 & Signifikan \\
$\mathrm{Y} 1 \rightarrow \mathrm{Y} 2$ & 0.247 & 0.074 & 3.335 & 0.001 & Signifikan \\
\hline
\end{tabular}

Sumber : Hasil Olahan Data SPSS, Lampiran

Keterangan :

$$
\begin{aligned}
\text { Y2 } & =\text { Pelayanan Publik } \\
\text { Y1 } & =\text { Kepuasan Kerja Karyawan } \\
\mathrm{X} 1 & =\text { Budaya Organisasi } \\
\mathrm{X} 2 & =\text { Kepemimpinan } \\
\mathrm{X} 3 & =\text { Motivasi }
\end{aligned}
$$

Tabel 3 mendeskripsikan bahwa budaya organisasi dan motivasi berpengaruh signifikan terhadap kepuasan kerja karyawan, sedangkan kepemimpinan tidak berpengaruh signifikan terhadap kepuasan kerja karyawan. Selanjutnya diketahui juga bahwa kepemimpinan, motivasi, dan kepuasan kerja karyawan berpengaruh signifikan terhadap pelayanan publik, namun budaya organisasi secara langsung berpengaruh tidak signifikan terhadap pelayanan publik rumah sakit.

Untuk lebih jelasnya, hasil ringkasan koefisien jalur dapat digambarkan dengan gambar 2 . 


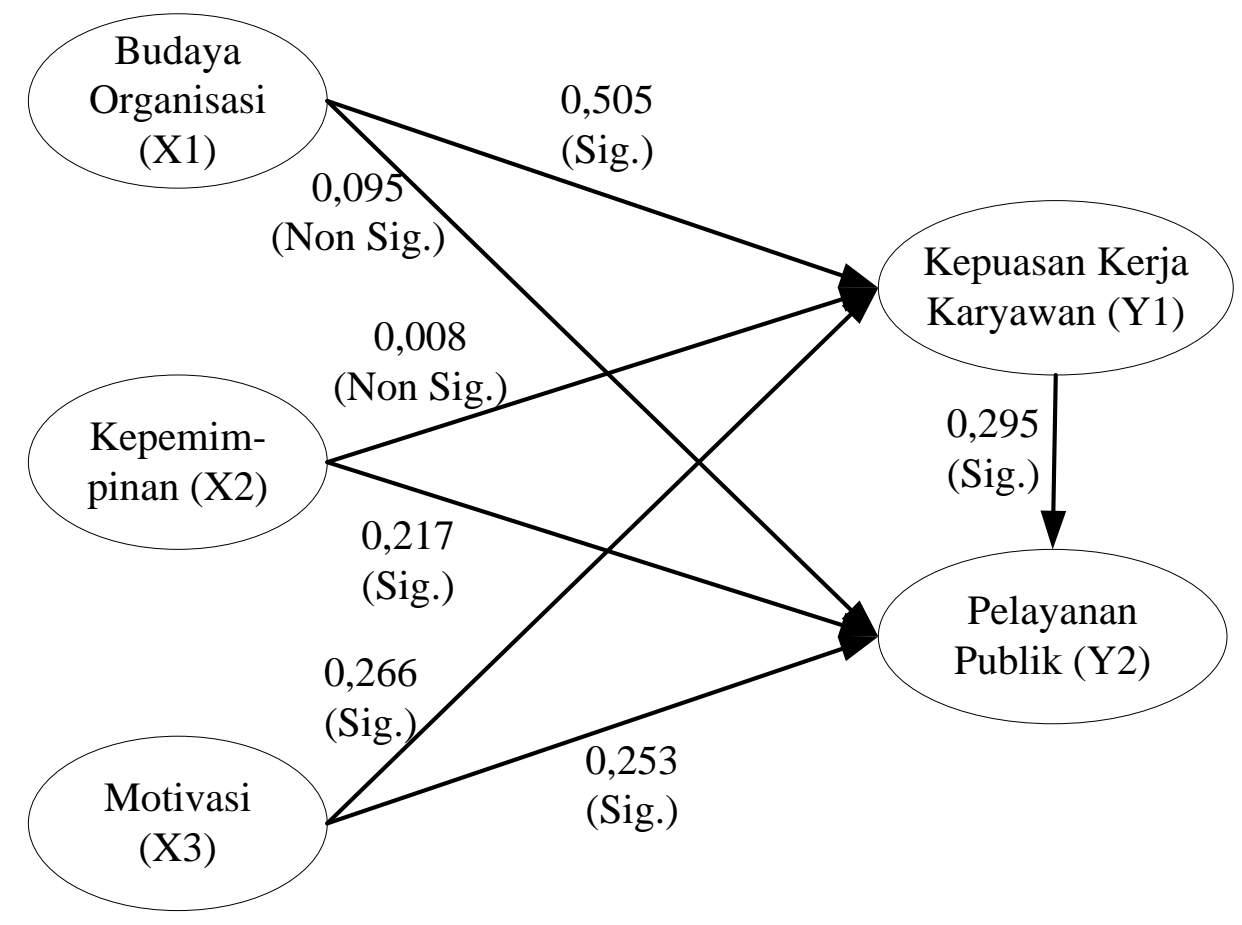

Gambar 2

\section{Koefisien Jalur Atas Model Penelitian}

\section{Pengaruh Tidak Langsung}

Pengujian pengaruh tidak langsung, atau mediasi dapat dilakukan dengan uji Sobel. Terdapat tiga hubungan pengaruh tidak langsung pada penelitian ini, yaitu pengaruh tidak langsung variabel budaya organisasi, kepemimpinan, dan motivasi terhadap pelayanan publik melalui kepuasan kerja karyawan. Adapun perhitungan uji Sobel dengan ringkas ditampilkan pada Tabel 5.20 berikut.

Tabel 4

Ringkasan Pengujian Mediasi (Uji Sobel)

\begin{tabular}{lcccc}
\hline Jalur Mediasi & $\begin{array}{c}\text { Koef. Reg. } \\
\text { Standar }\end{array}$ & $\begin{array}{c}\text { Standard } \\
\text { Error }\end{array}$ & t hitung & Keterangan \\
\hline $\mathrm{X} 1 \rightarrow \mathrm{Y} 1 \rightarrow \mathrm{Y} 2$ & 0.149 & 0.052 & 2.840 & Signifikan \\
$\mathrm{X} 2 \rightarrow \mathrm{Y} 1 \rightarrow \mathrm{Y} 2$ & 0.002 & 0.031 & 0.075 & Non Signifikan \\
$\mathrm{X} 3 \rightarrow \mathrm{Y} 1 \rightarrow \mathrm{Y} 2$ & 0.075 & 0.033 & 2.233 & Signifikan \\
\hline
\end{tabular}

Sumber: Lampiran

Berdasarkan Tabel 4 serta diketahui bahwa t-tabel senilai 1,658 maka dapat disimpulkan bahwa pengaruh tidak langsung budaya organisasi dan motivasi 
Ni Putu Lilyana, Nyoman Djinar Setiawina, Analisis Faktor Penentu Kepuasan.........

terhadap pelayanan publik melalui mediasi kepuasan kerja adalah signifikan. Sedangkan untuk pengaruh tidak langsung kepemimpinan terhadap pelayanan publik melalui mediasi kepuasan kerja bersifat tidak signifikan.

\section{PEMBAHASAN}

\section{1) Pengaruh Budaya Organisasi, Kepemimpinan, dan Motivasi Terhadap} Kepuasan Kerja Karyawan Rumah Sakit di Kabupaten Jembrana

Hasil penelitian menunjukkan bahwa budaya organisasi dan motivasi berpengaruh positif secara langsung terhadap kepuasan kerja karyawan rumah sakit di Kabupaten Jembrana.

Semakin baik budaya organisasi dan motivasi, maka akan mampu meningkatkan kepuasan kerja karyawan. Budaya organisasi akan dicerminkan oleh integrasi, rasionalitas serta solidaritas antara karyawan di rumah sakit. Demikian halnya motivasi, dapat dinilai dari faktor motif, harapan dan insentif. Contoh dengan adanya insentif, maka karyawan akan memiliki rasa kepuasan kerja. Demikian halnya bila karyawan memiliki harapan mengenai karier dalam bekerja maka kepuasan kerja juga akan meningkat.

Kondisi kepemimpinan ternyata tidak mempengaruhi secara signifikan kepuasan kerja karyawan. Hal ini dikarenakan tugas-tugas rutin yang dilaksanakan karyawan tidak terlalu dipengaruhi oleh faktor kepemimpinan. Apalagi dalam beberapa kelompok pekerjaan yang menyebabkan ketika karyawan bekerja tidak selalu ada pimpinan di rumah sakit. Inilah yang mengakibatkan kurangnya komunikasi dan keterkaitan antara karyawan rumah sakit dengan kepemimpinan.

2) Pengaruh Budaya Organisasi, Kepemimpinan, Motivasi, dan Kepuasan Kerja Karyawan, Terhadap Pelayanan Publik Rumah Sakit di Kabupaten Jembrana

Berdasarkan hasil penelitian, diketahui bahwa kepemimpinan, motivasi dan kepuasan kerja karyawan secara langsung berpengaruh positif dan signifikan 
terhadap pelayanan publik rumah sakit di Kabupaten Jembrana. Sedangkan budaya organisasi tidak berpengaruh signifikan terhadap pelayanan publik rumah sakit di Kabupaten Jembrana.

Pelayanan publik pada rumah sakit di Kabupaten Jembrana diberikan prsepsi cukup/sedang oleh responden, baik untuk indikator adaptabilitas layanan, maupun sifat layanan. Pelayanan yang diberikan oleh rumah sakit Jembrana memang masih perlu dioptimalkan, terutama terkait dengan kualitas kerja karyawan. Berdasarkan hasil observasi, diketahui bahwa karyawan dalam memberikan pelayanan perlu meningkatkan keramahan terhadap pasien. Selain itu karyawan perlu lebih informatif dalam memberikan pelayanan.

Peningkatan kepemimpinan, motivasi, dan kepuasan kerja karyawan akan mampu juga meningkatkan kualitas pelayanan publik rumah sakit di Kabupaten Jembrana. Pelayanan publik merupakan bentuk pelayanan baik bagi pasien maupun pengunjung rumah sakit. Kualitas pelayanan merupakan muara dari pelaksanaan perorganisasian suatu rumah sakit. Bagaimana kepemimpinan mampu menyusun suatu kebijakan tentang mekanisme pelayanan yang baik. Faktor motivasi dan kepuasan kerja akan menentukan bagaimana karyawan memberikan pelayanan publik.

Budaya organisasi ternyata tidak terlalu mempengaruhi pelayanan publik yang diberikan di rumah sakit. Kondisi pengaturan organisasi tidak langsung menentukan kualitas pelayanan publik dirumah sakit. Semakin rumit budaya organisasi belum menjadi jaminan pelayanan akan menjadi baik, demikian sebaliknya.

Hasil penelitian ini didukung oleh penelitian sebelumnya yang dimuat dalam jurnal "Pengaruh Pengukuran Kinerja, Budaya Organisasi dan Dukungan. Organisasional terhadap Kinerja Pegawai di Unit-Unit Pelayanan Publik Kabupaten. Sukoharjo"(Prawesti, 2010), yaitu variabel kepemimpinan, budaya organisasi tidak berpengaruh terhadap pelayanan publik. Demikian halnya tentang hasil penelitian yang tidak sesuai dengan teori. Hal ini juga diperkuat dengan oleh Bapak Suastawan, pasien rumah sakit dalam wawancara pada tanggal 22 Desember 2017 bahwa: 
Ni Putu Lilyana, Nyoman Djinar Setiawina, Analisis Faktor Penentu Kepuasan.........

"Ketidakpuasan pasien menjadi prioritas utama penanganan manajemen rumah sakit ini, seperti keluhan terhadap rumah sakit, berikut pelayanan yang dilakukan oleh tenaga kesehatannya (dokter, perawat, apoteker, psikolog dan lainnya) dan struktur sistem perawatan kesehatan (biaya, sistem asuransi, kemampuan dan prasarana pusat kesehatan dan lain-lain). Dalam hal ini pasien mengharapkan interaksi yang baik, sopan, ramah, nyaman dengan tenaga kesehatan, sehingga kompetensi, kualifikasi serta kepribadian yang baik dari pelayan kesehatan. Faktor utama dalam mempengaruhi kepuasan pasien adalah lengkapnya peralatan medik, bangunan dan fasilitas rumah sakit yang memadai, kelengkapan sarana pendukung dalam pelayanan."

\section{3) Peran Kepuasan Kerja Karyawan Dalam Memediasi Pengaruh Budaya Organisasi, Kepemimpinan, dan Motivasi Terhadap Pelayanan Publik Rumah Sakit di Kabupaten Jembrana}

Hasil penelitian menunjukkan bahwa kepuasan kerja memediasi secara signifikan pengaruh budaya organisasi dan motivasi terhadap pelayanan publik rumah sakit di Kabupaten Jembrana, namun tidak signifikan memediasi pengaruh kepemimpinan terhadap pelayanan publik rumah sakit di Kabupaten Jembrana.

Bila ditinjau bahwa secara langsung budaya organisasi berpengaruh signifikan terhadap pelayanan publik, dan secara tidak langsung juga berpengaruh signifikan, maka sifat mediasi kepuasan kerja pada pengaruh budaya organisasi terhadap pelayanan publik rumah sakit di Kabupaten Jembrana bersifat mediasi parsial (partial mediation).

Selanjutnya dengan memperhatikan bahwa secara langsung kepemimpinan tidak berpengaruh signifikan terhadap pelayanan publik, sedangkan secara tidak langsung berpengaruh signifikan, maka sifat mediasi kepuasan kerja pada pengaruh kepemimpinan terhadap pelayanan publik rumah sakit di Kabupaten Jembrana bersifat mediasi penuh (full mediation).

Bila ditinjau bahwa secara langsung motivasi berpengaruh signifikan terhadap pelayanan publik, dan secara tidak langsung juga berpengaruh signifikan, 
maka sifat mediasi kepuasan kerja pada pengaruh motivasi terhadap pelayanan publik rumah sakit di Kabupaten Jembrana bersifat mediasi parsial (partial mediation).

Hal ini juga diperkuat dengan oleh Bapak I Gede Dwipayana, direktur rumah sakit umum Negara dalam wawancara pada tanggal 22 Desember 2017 bahwa:

"Peningkatan kinerja pegawai dalam hal ini dilakukan dengan jalan merubah/memperbaiki budaya organisasi yang lebih baik karena budaya organisasi secara positif signifikan mempengaruhi kinerja. Cara lain untuk meningkatkan kinerja pegawai yaitu dengan meningkatkan motivasi kerja karena motivasi kerja berpengaruh secara positif signifikan terhadap kinerja pegawai."

\section{Simpulan}

Berdasarkan penelitian diatas, dapat disimpulkan hal-hal sebagai berikut :

1) Budaya organisasi memberikan pengaruh yang bersifat positif yang secara langsung dan signifikan terhadap kepuasan kerja karyawan rumah sakit di Kabupaten Jembrana.

2) Kepemimpinan secara langsung tidak berpengaruh signifikan terhadap kepuasan kerja karyawan rumah sakit di Kabupaten Jembrana.

3) Motivasi memberikan pengaruh yang bersifat positif yang secara langsung dan signifikan terhadap kepuasan kerja karyawan rumah sakit di Kabupaten Jembrana.

4) Budaya organisasi tidak berpengaruh secara langsung dan signifikan terhadap pelayanan publik rumah sakit di Kabupaten Jembrana. Artinya pelayanan publik dalam hal pelayanan rumah sakit akan mengalami hambatan jika nilainilai budaya organisasi tidak dijadikan sebagai norma bersama dalam melayani masyarakat.

5) Kepemimpinan memiliki pengaruh yang positif dan signifikan terhadap pelayanan publik rumah sakit di Kabupaten Jembrana.

6) Motivasi secara langsung memberikan pengaruh positif dan signifikan terhadap pelayanan publik rumah sakit di Kabupaten Jembrana. 
Ni Putu Lilyana, Nyoman Djinar Setiawina, Analisis Faktor Penentu Kepuasan.........

7) Kepuasan kerja karyawan berpengaruseh yang positif secara langsung dan secara signifikan terhadap pelayanan publik rumah sakit di Kabupaten Jembrana. Artinya fungsi pelayanan publik yang banyak dikenal dengan sifat birokratis dan banyak mendapat keluhan dari masyarakat karena masih belum memperhatikan kepentingan masyarakat penggunanya.

8) Kepuasan kerja karyawan memediasi secara signifikan pengaruh budaya organisasi terhadap pelayanan publik rumah sakit di Kabupaten Jembrana.

9) Kepuasan kerja karyawan tidak memediasi secara signifikan pengaruh kepemimpinan terhadap pelayanan publik rumah sakit di Kabupaten Jembrana.

10) Kepuasan kerja karyawan memediasi secara signifikan pengaruh motivasi terhadap pelayanan publik rumah sakit di Kabupaten Jembrana.

\section{Saran}

Dari hasil penelitian dan simpulan yang telah didapat, maka saran/rekomendasi sebagai berikut :

1) Manajemen rumah sakit di Kabupaten Jembrana perlu memberikan training kepemimpinan bagi kalangan pejabat untuk mengoptimalkan fungsi kepemimpinan dalam meningkatkan kepuasan kerja karyawan serta kualitas pelayanan publik yang akan diberikan oleh karyawan rumah sakit, baik kepada pasien maupun pengunjung.

1) Faktor motivasi kerja karyawan perlu ditingkatkan, termasuk pemberian insentif, khususnya bagi karyawan yang berprestasi sehingga dapat meningkatkan motivasi dan kepuasan kerja karyawan.

2) Selain itu sistem jenjang karier dalam suatu organisasi, khususnya di rumah sakit juga perlu diperhatikan oleh manajemen, sehingga karyawan akan termotivasi menunjukkan performance terbaiknya dalam memberikan pelayanan.

3) Untuk lebih meningkatkan pelayanan publik di Rumah Sakit Jembrana, sebaiknya nilai-nilai budaya organisasi selalu dijadikan sebagai panduan dalam memberikan pelayanan pada masyarakat. 


\section{REFERENSI}

Azwar, Azrul. 1996. "Pengantar Administrasi Kesehatan”. Jakarta: Binarupa Aksara.

Azwar. 2010. Pengaruh Motivasi Terhadap Kepuasan Kerja Pegawai Badan Koordinasi Keluarga Berencana Nasional Kabupaten Muara Enim. Jurnal Manajemen \& Bisnis Sriwijaya Vol.3 No 6.

Adnyana, Ngurah, dan Yohanes Sukrislismono. 2005. To Be Word Class Service (Proses Metamorfosis PLN Distribusi Bali). Denpasar: Penerbit Jala.

Arawati Agus 2007. Exploratory Study of Service Quality in The Malaysian Publik Service Sector. Faculty of Economics and Business by NationalUniversity of Malaysia from:http://proquest.umi.com/pqdweb.

Ariani, Dorothea Wahyu. 2003. Manajemen Kualitas Pendidikan Sisi Kualitatif. Jakarta: Ghalia Indonesia.

Arianto. 2004. Pengaruh Promosi, Tindakan Supervisi, Upah Dan Tipe Personalitas Terhadap Kinerja dan Keinginan Berpindah Kerja Staf Auditor Melalui Kepuasan Kerja: Studi Pada Kantor Akuntan Publik di Surabaya. Tesis. Magister Manajemen Universitas Airlangga Surabaya.

Asaad, M. 2001. Psikologi Industri: Seri Sumber Daya Manusia. Edisi Keempat. Cetakan Keenam. Yogyakarta: Liberty.

Beach, 1993.Leadership. New York: Harper Collins.

Bliss, 1999. Transformational Leadership and the Performace of Research and Development Project Groups.Journal of Management.

Bellou, Victoria. 2006. Enhancing Service Quality in a Hospital Setting. Macedona of University. ProQuest. 2007.

Borzago, Tortia. 2006. Worker Motivations, Job Satisfaction, and Loyality in Publik and Nonprofit Social Services. Pro Quest ABI/INFROM 9R) Research.

Curral. S.C. 2005. Pay Satisfaction and Outcome Organization. Psychologi Journal. Vol. 58; pp. 613-640.

Dessler, Gary. 2004. Manajemen Sumber Daya Manusia. Edisi kesembilan. Jakarta: PT. Indeks Kelompok Gramedia.

Djojodibroto, R.D. 2004. Orientasi Umum Kepemimpinan, Indogement, LPA FIA Unibraw. 
Ni Putu Lilyana, Nyoman Djinar Setiawina, Analisis Faktor Penentu Kepuasan.........

Dierdorff, Erich;Robert S.Rubin. 2007. Carelessness and Discriminality In Work Role Requirment Judgements : Influences of Role Ambiguity and Cognitive Complexity. ProQuest Psychology Journal. Chigago : De Paul University.

Ghozali, Imam. 2002. Aplikasi Analisis Multivariate Dengan Program SPSS. Edisi Kedua. Semarang: Bagian Penerbit Universitas Diponogoro. 2004. Model Persamaan Struktural Konsep dan Aplikasi dengan AMOS Ver.5.0. Semarang : Badan Penerbit Universitas Diponegoro.

Gieter et al. 2006. Dimensionality Of The Pay Satisfaction Questionnaire : A Validation Study In Belgium. Psychological Report. Belgium : Vrijee Universiteit Brussel.

Gorda, I Gusti Ngurah. 2006. Manajemen Sumber Daya Manusia. Cetakan Ketiga. Denpasar : Astabrata Bali.

Hair, J.F., Anderson, RE., Tatham, R.L, Black, W.C. 1995. Multivariate Data Analysis (fourth ed.). New Jersey : Prentice-Hall.

Handoko, T,H. 2001. Manajemen Personalia dan Sumber Daya Manusia. Yogyakarta : BPFE Press.

Hasibuan,SP,M. 2007. Manajemen Sumber Daya Manusia. Edisi Revisi. Cetakan Kesepuluh. Jakarta: Bumi Aksara.

Hardiyansyah, 2011. Hubungan Antara Persepsi Kepemimpinan Transformasional dan Transaksional dengan Kepuasan Kerja Karyawan. Prespektif Jurnal Fakultas Psikologi Universitas Bina Darma Palembang Volume 1 Desember 2011.

Irmin, Soejitno. 2004. Hand out Untuk Mengelola SDM. Cetakan Pertama. Yayasan : Seyma Media.

Istijanto. 2006. Riset Sumber Daya Manusia. edisi kedua. Jakarta : PT. Gramedia Pustaka.

Journal Of international 2005. Leadership and Organization Studies, Kedlington. Des.Vol 27.ISS.8 Pg.1199.

Journal Of international 2006. Transformational and Transactional Leadership : Association With Attitudes Toward Evidence-Based Practice, Kedlington. Des.Vol 27.ISS.8 Pg.1199

Journal Of international 2002. Does The Transactional-Transformastional Leadership Paradigm Transcend Organizational and National Boundaries, Bernard M.Bass State University of New York at Binghamton. 
Kotter dan Heskett. 1992. .Human Resources.Edisi 10.Jakarta :SalembaEmpat.

Kreitner dan Kinicki A. 1995. Perilaku Organisasi, Versi Bahasa Indonesia. Edisi Pertama. Jakarta. Penerbit :Salemba Empat.

Koesmono, 2005. Pengaruh Budaya Organisasi Terhadap Motivasi dan Kepuasan Kerja Serta Kinerja Karyawan Pada Sub Sektor Industri Pengolahan Kayu Skala Menengah di JawaTimur.Jurnal Manajemen Kewirausahaan Vol 7 No 2 September, 171-188.

Kyoon Yoo, Dong. 2007. Perceived Service Quality: Analyzing Relationship Among Employees, Customer, and Financial Perfomance. Jeong Ah Park The International Journal of Quality \& Reliability Manajemen. from:http://proquest.umi.com/pqdweb.

Kumorotomo. 2008. Pengaruh Kepemimpinan Transformasional dan Transaksional serta Motivasi Kerja terhadap Kinerja. Jurnal Aplikasi Manajemen. Vol7, No. 1, Februari 2008.

Lagas. 2005. Pengaruh Kepemimpinan dan Motivasi Kerja Perawat terhadap Kualitas Pelayanan Kesehatan pada Rumah Sakit Santo Borromeus Bandung. (Thesis) Program Magister Manajemen Universitas Wijaya Putra Surabaya.

Lee, Andy H. 2006. Meansuring Job Satisfaction in Residential Aged Care. Australia; School of Publik Health, Curtin University (Online), (August 10,2007),

Luthans, Fred. 2006. Perilaku Organisasi Edisi 10. Yogyakarta: Penerbit ANDI.

Mahmudi. 2005. Manajemen Kinerja Sektor Publik. Yogyakarta: UPP AMP YKPN.

Mangkunegara, A.A. Anwar Prabu. 2006. Evaluasi Kinerja SDM. Cetakan Kedua. Bandung : PT. Refika Aditama.

Martoyo, Susilo.2000.Manajemen Sumber Daya Manusia. Edisi Keempat. Yogyakarta : BPFE

Maslow, A.H. 1970. Motivation and Personality. Harper and Row. New York.

Nawawi, Hadari.2001. Manajemen Sumber Daya Manusia (Untuk Bisnis yang Kompetitif). Yogyakarta. Penerbit Gadjah Mada University Press. 
Ni Putu Lilyana, Nyoman Djinar Setiawina, Analisis Faktor Penentu Kepuasan.........

Prasetyo, Edhi; M. Wahyuddin. 2007. Pengaruh Kepuasan dan Motivasi Kerja terhadap Produktivitas Kerja Karyawan Riyadi Selamet Palace di

Pasolong, Harbani. 2007. “Teori Administrasi Publik”. Bandung : Alfabeta

Robbins, 1996. PerilakuOrganisasi, Konsep, Kontroversi, Aplikasi. AlihBahasaolehHadyanaPujatmaka.Edisiketujuh.Prenhalindo. Jakarta.

Riduwan dan Engkos A. Kuncoro. 2007. Analisis Jalur (Path Analysis). Bandung : Penerbit Alfabeta.

. 2007. Metode dan Teknik Menyusun Tesis. Bandung : Penerbit Alfabeta.

Rivai, Veithzal, dan Ahmad Fawzi Mohd. Basri. 2005. Perfomance Appraisal (Sistem yang Tepat untuk Menilai Kinerja Karyawan dan Meningkatkan Daya Saing Perusahaan). Jakarta: PT. Raja Grafindo Persada.

. 2005. Manajemen Sumber Daya Manusia Untuk Perusahaan dari Teori ke Praktek. Cetakan Pertama. Jakarta : PT. Raja Grafindo Persada.

Robbins S,P. 2006. Perilaku Organisasi. Edisi Kesepuluh. Klaten : PT. Intan Sejati Klaten. . 2003. Organizational Behavior. 9th edition. New Jersey: Prentice Hall.

Surakarta. Publikasi Ilmiah. Program Pascasarjana Universitas Sebelas Maret Surakarta.

Safari,Triantoro. 2004. Kepemimpinan. Cetakan pertama. Surabaya : CV. Graha Ilmu.

Santoso, Singgih. 2004. Buku Latihan SPSS Statistik Multivariate, Cetakan Ketiga, Jakarta: PT. Elex Media Komputindo Kelompok Gramedia.

Sarwono, Jonathan. 2007. Analisis Jalur untuk Riset Bisnis dengan SPSS. Edisi pertama. Yogyakarta : CV. Andi Offset.

Schuler, Randall S. dan Jackson, Susan E, 1997. Manajemen Sumber Daya Manusia. Edisi Keenam. Jakarta Erlangga.

Sedarmayanti. 2007. Manajemen Sumber Daya Manusia : Reformasi Birokrasi . 2007. Manajemen Sumber Daya Manusia dan Produktivitas Kerja. Bandung. Penerbit Ilham Jaya.

Sekaran, Uma. 2003. Research Methods for Business a Skilling-Building Approach Fourth Edition. New York: Jhon Wiley and Sons. Inc. 